The Geneva Papers on Risk and Insurance, 18 (No. 69, October 1993), 423-425

\title{
Risk and Society: A View from Switzerland
}

\author{
by Robert Baumann*
}

1. Let me first summarize the special situation in Switzerland.

At present we still have a system of material supervision which calls for prior product approval and solvency monitoring, a security fund and security deposits.

The rejection of the European Economic Area treaty (the EEA) in December 1992 means there is at this moment no incorporation of the Phase $3 \mathrm{EC}$-guidelines on insurance.

The insurance agreement with the EC in the non-life area (in force with effect from 1.1.93) is still based, however, on the Phase 1 guidelines, that is freedom to set up subsidiaries, including reciprocity, solvency margins and tied assets.

Parliamentary consultations are currently taking place on what we call the "Swiss-lex" standards which will raise the underwriting guidelines up to Phase 2 . However, the insurance industry has not given its consent to proceed along these lines.

Parliamentary initiatives have emerged now within the context of the Phase 3 guidelines, such as liberalization of motor vehicle liability rates (including risks in personal lines business), to achieve far reaching deregulation in terms of European-wide compatibility, but for private insurers only. This without renouncing to the monopolies of the public insurance institutions (such as Cantonal fire insurance institutions), as would have been the case under the EEA treaty.

There is an additional feature, peculiar to Switzerland, which must also be taken into account in connection with consumer protection and its consequences for the insurance industry: The Consumer Price Controller.

In principle, he can investigate price increases in the private sector and, if necessary, reject them. Prior to 1991 however, prices which required the approval of government authorities were excluded from this system of monitoring. With effect from 1991 the Price Controller is also entitled to investigate such prices, for example the approval of insurance rates.

\footnotetext{
* Chairman of the Board, Bâloise-Holding, Basel. Paper presented at the 20 th General Assembly of the Geneva Association, Vienna, June 7, 1993.
} 
We have already had our first experience within this context last year when the Price Controller questioned the statistical assumptions for motor liability rates and interpreted these, in the "interest of the consumer", in such a way that, in his opinion, no increase in rates was justified for the main group of private cars. In fact, we do have a special committee which deals specifically with the calculations of rates and tariffs. This committee, comprising economists, automobile federations, consumer representatives and, in the minority, insurance representatives, evaluates the proposed rates and submits them for approval to the supervising authorities.

Fortunately, the supervisory authorities remained steadfast and ruled the Consumer Price Controller off-side.

2. It is specifically as a result of the special features in Switzerland - leaving aside the additional involvement of the Monopolies Commission - that we are able to see where this situation is leading, a situation which can be summarised as follows:

Price monitoring, which sails under the banner of "consumer protection", is likely to be biased in favour of the interests of the consumer or the policyholder. Quite simply that means the lowest possible premiums for the widest possible insurance cover. This does not make allowance for the insurance company's ability to maintain its long term liquidity and solvency, although these must surely also be in the interests of the consumer.

Consequently, we feel compelled to ask the questions as to whether total deregulation might not lead to the very same thing.

When posing this question, it would also be interesting to know whether a statement made by Sir Leon Brittan at the last World Insurance Congress in Madrid, does not represent a squaring of the circle so-to-speak.

I quote :

"To achieve this end, the Directives must ensure that high prudential standards are maintained. We want policyholders throughout the EC to profit from the widest possible choice of insurance products at the most competitive prices. But that must go hand in hand with policyholder confidence in the products on offer, and in the companies which sell them."

I cannot help stating my opinion that, with all the diverse requirements as set out by Sir Leon Brittan, his wish is indeed father to the thought.

3. I would therefore like to make the following comments on a free insurance market and the demands of consumer protection and raise a number of hypotheses for the subsequent discussion.

a) The liberalisation of the insurance market, that is the introduction of the standard licence, will create increased competition. First of all, increased competition means a greater diversity of products without even mentioning lower prices at this stage. No-one would wish to dispute this principle of the free market economy. Product diversity will make market transparency all the more difficult for the consumer. It is, however, most unlikely that the consumer will be able to compare the apparent difference - the price since each product is structured on a different price/performance ratio.

The result: If the range of products and services available fails to provide the client with the transparency he needs, he is more and more dependent on advice. However, advice costs money. The question is, who should provide this service. 
b) Increased competition will bring its own pressure to bear on prices. Deregulation, that is amongst other things, the abolition of material supervision. And it will make it easier for the insurer to reduce prices. The question arises however, as to whether price reductions are a result of rationalisation and an increased share of the market. Or whether cut-price-operators - after a certain amount of initial success - will have to revert to questionable methods in order to remain solvent; for example

- reduction in or even cancellation of participation in profits for life assurance policies,

- one branch or sector subsidising another,

- a reduction in the quality of products such as:

the incorporation of high and hidden deductibles, the rejection of claims,

curtailing the level of benefits or including more restrictive conditions.

The result: The client is hardly going to be able to analyse the commercial attitudes of one insurance company compared to another. It is also highly unlikely that analyses of quality standards will be possible without the help of professional advice.

Consequently, the consumer will be assuming far greater risks when concluding insurance than was the case in the past.

c) The risks that the insured is assuming are of varied nature:

Either the promise of coverage and benefits made by the insurer may be insufficient in the event of a claim.

This is where, in my opinion, internal self-regulation within the insurance industry must come into play. When the insurers can demonstrate clarity in the standards of insurance technology, when they can raise the training qualifications of their sales personnel and when they can create distinct assessment criteria for insurance products, only then will they be able to single out and expose the black sheep of the insurance industry.

Perhaps you can see other measures for the insurer to take.

Or the insurer becomes insolvent and, in the worst case scenario, this leads to the insured or the damaged party losing their cover or their savings.

This area calls then for government supervision. A check on solvency in itself, is not sufficient; this always comes too late and will be unable to prevent a dangerous development. The insured will therefore have to learn by his mistakes, or, in insurance terms, his losses.

In my opinion, the weapons of the supervisory authorities for protecting the consumer have been blunted by deregulation; supporting measures such as those contained in insurance law are still unable to be applied and in my oppinon, the supervisory authorities are not yet prepared for their new task.

No doubt the representatives of the supervisory authorities present today will wish to make their own comment on this.

The less critical supporters of the free market economy and the consumer organisations are making every effort to get rid of all regulating influences within the insurance industry. After-effects are bound to appear and those same people will then be calling for tighter regulation and supervision.

This is also something which should be avoided. 